Pak. j. sci. ind. res. Ser. A: phys. sci. 201558 (2) 99-105

\title{
DSC Cure Kinetics of an Unsaturated Polyester Resin Using Empirical Kinetic Model
}

\author{
Iram Abdullah \\ Pak-Korea Garment Technology Institute, SFDAC Building, ST \# 2/30, Korangi Industrial Area, \\ Korangi, Karachi, Pakistan
}

(received May 25, 2013; revised February 15, 2014; accepted February 20, 2014)

\begin{abstract}
In this paper, the kinetics of curing of unsaturated polyester resin initiated with benzoyl peroxide was studied. In case of unsaturated polyester (UP) resin, isothermal test alone could not predict correctly the curing time of UP resin. Therefore, isothermal kinetic analysis through isoconventional adjustment was used to correctly predict the curing time and temperature of UP resin. Isothermal kinetic analysis through isoconversional adjustment indicated that $97 \%$ of UP resin cures in $33 \mathrm{~min}$ at $120^{\circ} \mathrm{C}$. Curing of UP resin through microwaves was also studied and found that $67 \%$ of UP resin cures in $1 \mathrm{~min}$ at $120{ }^{\circ} \mathrm{C}$. The crosslinking reaction of UP resin is so fast at $120{ }^{\circ} \mathrm{C}$ that it becomes impossible to predict correctly the curing time of UP resin using isothermal test and the burial of $\mathrm{C}=\mathrm{C}$ bonds in microgels makes it impossible to be fully cured by microwaves at $120^{\circ} \mathrm{C}$. The rheological behaviour of unsaturated polyester resin was also studied to observe the change in viscosity with respect to time and temperature.
\end{abstract}

Keywords: isothermal kinetic, unsaturated polyester resin, microwave curing, rheology

\section{Introduction}

The unsaturated polyester (UP) resin is the thermosetting material used for composite applications such as the preparation of structural parts of automobiles, building materials, coating materials, electrical parts, etc. The thermosetting resins generally contain reactant groups. The composition of these reactant groups influences not only the curing rate but also the final mechanical properties of the material. Therefore, their processing requires an understanding of the reaction kinetics of polymerisation during cure. The curing is a highly exothermal reaction and can be monitored by thermal analysis as the differential scanning calorimetry (DSC). Such kinetic studies allow us to determine how much, how fast and at which temperature range heat is released. Furthermore, it gives fundamental data on reaction rate and degree on conversion of reactants which is required to fully cure resin in composite moulding techniques (Bu et al., 2014; Vargas et al., 2012; Wuzella et al.,2011; Jankoviæ, 2010).

In DSC, it is common to assume that the evolution of exchanged heat is strictly proportional to the rate of the global chemical reaction (Martine et al., 1997), at any instant, as follows:

$\mathrm{dH} / \mathrm{dt}=\Delta \mathrm{H}_{\mathrm{R}}[\mathrm{d} \alpha / \mathrm{dt}]$

Author for correspondence; E-mail: i_tayyab@hotmail.com
Where:

$\mathrm{dH} / \mathrm{dt}=$ the heat generated by time unit or heat flow, $\mathrm{d} \alpha / \mathrm{dt}=$ the rate of reaction, and

$\Delta \mathrm{Hr}=$ the heat of reaction obtained as the area of the DSC thermogram.

Therefore, it is possible to evaluate the reaction rate dá/dt at time $t$, and degree of conversion $\alpha$ reached at time $t$, by mean of the following expression:

$\mathrm{d} \alpha / \mathrm{dt}=1 / \Delta \mathrm{H}_{\mathrm{R}}[\mathrm{dH} / \mathrm{dt}], \alpha=\Delta \mathrm{H}_{\mathrm{t}} / \Delta \mathrm{H}_{\mathrm{R}}$

Where:

$\Delta \mathrm{H}_{\mathrm{t}}=$ the heat released up to the time $\mathrm{t}$, and it can be obtained by integration of calorimetric signal $\mathrm{dH} / \mathrm{dt}$ up to time $\mathrm{t}$.

The unsaturated polyester resin is generally a co-polymer of anhydride with diols. The double bond of unsaturated polyesters reacts with a monomer, usually, resulting in a 3-D cross-linked structure (Fink, 2013). The exothermic heat generated during the curing of resin is proportional to the number of double bonds that have reacted with styrene in the system. The maximum conversion is reached when all the double bonds of polyester that can react have reacted with the styrene. Since, the reaction rate is directly proportional to rate of heat generation $\mathrm{dH} / \mathrm{dt}$, the reaction rate and degree of conversion can be evaluated by expression (2). 
The purpose of this study was to stimulate the process of curing of UP resin by means of DSC calorimetry. Non-isothermal experiments were made at different heating rates; the experimental curves were fitted using an empirical kinetic model. This model gave good theoretical predictions with experimental results. These predictions were then correlated with actual microwave curing of UP resin.

In general kinetic model relates the rate of reaction $\mathrm{d} \alpha / \mathrm{dt}$ to some function of $\alpha$ and T. It is commonly accepted in the kinetic analysis of chemical reactions by thermal analysis that any chemical process of reaction will obey of rate law of the form (Martin et al., 1997; Salla and Ramix, 1994):

$\mathrm{d} \alpha / \mathrm{dt}=\mathrm{k}(\mathrm{T}) f(\alpha)$

Where:

the functional dependence upon $\alpha$ is separated from the dependence upon T. Here, $\mathrm{k}(\mathrm{T})=$ the rate constant which is given by an Arrhenius type equation depends on temperature

$\mathrm{k}=\mathrm{k}_{0} \exp [-\mathrm{E} / \mathrm{RT}]$

Where:

$\mathrm{A}=$ the Arrhenius frequency factor, $\mathrm{E}=$ the activation energy, $\mathrm{R}=$ the universal gas constant and $\mathrm{T}$ is the curing temperature.

Thus for one reaction, using a multiple linear regression, it is possible to determine the kinetic parameters for DSC exothermic peak obtained from either isothermal or nonisothermal measurements. When the process is isothermal the temperature constant, but in non-isothermal process temperature usually increases according to a constant heating $\beta=\mathrm{dT} / \mathrm{dt}\left(\mathrm{T}=\mathrm{T}_{0}+\beta \mathrm{t}\right)$. The isothermal rate expression obtained in isothermal measurements is theoretically more precise than non-isothermal rate expression. However, non-isothermal DSC measurement is in general less time consuming than isothermal DSC measurement and thus more attractive than isothermal measurement.

In isothermal DSC measurement, it is not necessary to know the equation for $f(\alpha)$, which may vary during the curing process. Applying the iso-conversional adjustment (Martin et al., 1997; Salla and Ramix, 1995;1994), given by the expression $\ln \mathrm{t}=\mathrm{A}+\mathrm{E} / \mathrm{RT},(\alpha=\mathrm{ct})$ at a series of temperatures, it is possible to determine the activation energy at different degree of conversion from the slope of this linear relationship and thus to see how the reaction process evolves. Using this method activation energy is obtained which depends upon the degree of conversion. On the other hand when non-isothermal experiments are performed, the function $f(\alpha)$ has to be specified. With regard to $f(\alpha)$, auto-catalysed mechanism of reaction is used to characterise the curing of thermosetting resin. The auto-catalysed function of $f(\alpha)$ is given by the expression:

$f(\alpha)^{\mathrm{m}}(1-\alpha)^{\mathrm{n}}$

Where:

$\mathrm{m}$ and $\mathrm{n}$ are the orders of reaction; therefore the experimental data will be fitting according the next expression:

$\mathrm{d} \alpha / \mathrm{dt} A \mathrm{e}^{[-\mathrm{E} / \mathrm{RT}]} \alpha^{\mathrm{m}}(1-\alpha)^{\mathrm{n}}$

The constants A, E, $\mathrm{m}$ and $\mathrm{n}$ are the kinetic parameters that must be determined. This expression can be written in logarithmic form:

$\ln (\mathrm{d} \alpha / \mathrm{dt})=\ln \mathrm{A}-\mathrm{E} / \mathrm{RT}+\mathrm{m} \ln +\operatorname{nln}(1-\alpha)$

\section{Materials and Methods}

Materials and colorimetric instrumentation. Norpol 420-100 resin system used in this study was supplied by Rachold Chemicals. This resin system contains 75\% polyester resin and $25 \%$ styrene with no added accelerator. Benzoyl peroxide was used as $1 \%$ by the weight of resin as an initiator.

Calorimetric measurements. The calorimetric measurements were carried out using TA Instruments Thermal Analyst DSC Standard Cell.

All DSC measurements were performed in a hermetic aluminium pans. A standard sample was prepared by mixing $10 \mathrm{~g}$ of UP resin with a fixed portion of initiator (100: 1). The required amount of sample $20 \mathrm{mg}$ was weighted into a sample pan which was then sealed and placed in the DSC for each measurement. After each run, weight of the sample was determined to check any weight loss due to evaporation of styrene monomer. No considerable weight loss was observed.

\section{Results and Discussion}

The dynamic scan was performed from- $50{ }^{\circ} \mathrm{C}$ to $300{ }^{\circ} \mathrm{C}$ using nitrogen atmosphere at $50 \mathrm{~mL} / \mathrm{min}$ and a heating rate of $10{ }^{\circ} \mathrm{C} / \mathrm{min}$. Figure 1 shows the typical dynamic thermogram for curing polyester resin in temperature range $-50{ }^{\circ} \mathrm{C}$ to $300{ }^{\circ} \mathrm{C}$. Several UP resin samples were tested at heating rate $10^{\circ} \mathrm{C} / \mathrm{min}$ and the peak temperature position observed was in the range $113^{\circ} \mathrm{C}-117^{\circ} \mathrm{C}$. The heat of reaction estimated from area under the curve was $230 \mathrm{~J} / \mathrm{g}$. 


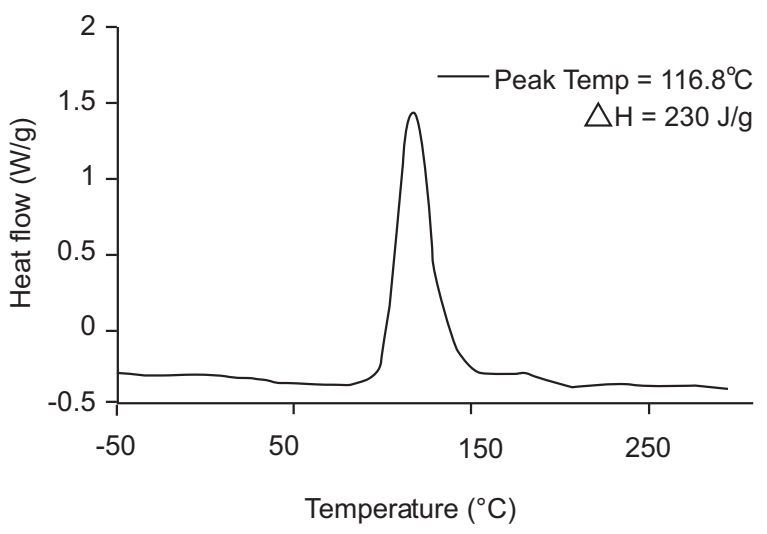

Fig. 1. Typical dynamic thermogram for curing of unsaturated polyester resin in temperature range -50 to $300{ }^{\circ} \mathrm{C}$.

Figure 1 also shows two peaks for trace; the first is greater in area than the second peak. First peak is about $80 \%$ of the total area; which starts at lower temperature as the free radicals are produced to initiate the polymerisation reaction. The second peak appears at high temperature when the DSC trace suggests that curing of PU resin is completed. Avella et al., (1985) suggested that the first peak indicates the copoly-merisation of styrene with polyester unsaturation, while the second peak indicates the homo-polymerisation of styrene. This is arguable since in the absence of initiator UP resin polymerises in the temperature range of $180^{\circ} \mathrm{C}$ $210^{\circ} \mathrm{C}$. Furthermore, pure polystyrene polymerises in the temperature range of $140{ }^{\circ} \mathrm{C}-310^{\circ} \mathrm{C}$ (Severini and Gallo, 1985; Horic et al., 1969, Lewis et al., 1948). Due to the complexity of the reaction; only the first peak is used to determine the heat of reaction, peak temperature and later degree of cure.

Figure 2 shows the isothermal thermogram of UP resin cured in DSC at a temperature $120{ }^{\circ} \mathrm{C}$ in nitrogen

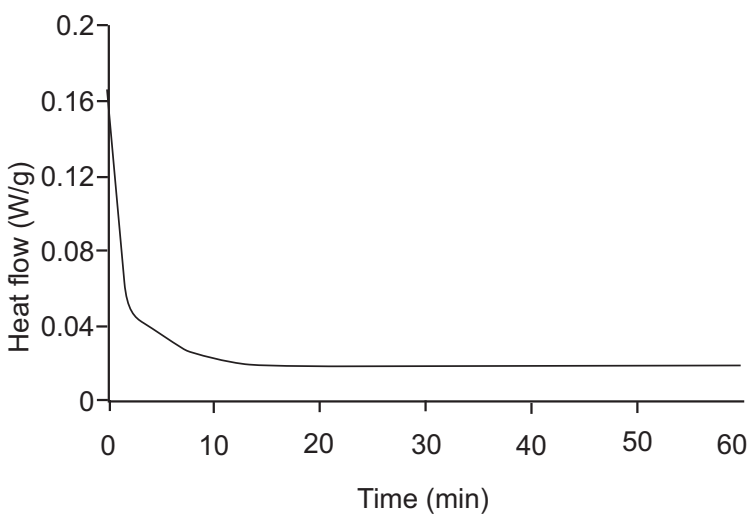

Fig. 2. Isothermal thermogram of unsaturated polyester resin at $120{ }^{\circ} \mathrm{C}$ for $60 \mathrm{~min}$. atmosphere $(50 \mathrm{~mL} / \mathrm{min})$. The curing time given was $60 \mathrm{~min}$. The reaction enthalpy measured was $23.4 \mathrm{~J} / \mathrm{g}$ and the resin sample was fully cured in $15 \mathrm{~min}$. Re-test (Fig. 3) confirms that the UP resin is fully cured considering the first peak. $188.9^{\circ} \mathrm{C}$ is the peak temperature of second peak which shows that sum of residual heat and iso-thermal heat $(23.4 \mathrm{~J} / \mathrm{g})$ is much lower than the dynamic heat (230 $\mathrm{J} / \mathrm{g}$ ). This indicates that either the isothermal heat or the residual heat is not correct, since their sum should be equal to dynamic heat. Several authors attributed that part of heat that cannot be registered isothermally by the calorimeter is that which is lost during the stabilisation of calorimeter. Cure kinetics were therefore, determined by mean of an empirical (autocatalytic) model.

The isothermal cure in DSC was performed at temperatures range $90{ }^{\circ} \mathrm{C}-120{ }^{\circ} \mathrm{C}$ as shown in Fig. 4. The required properties i.e. the degree of conversion and the reaction rate $\mathrm{d} \alpha / \mathrm{dt}$ as time or temperature functions were evaluated

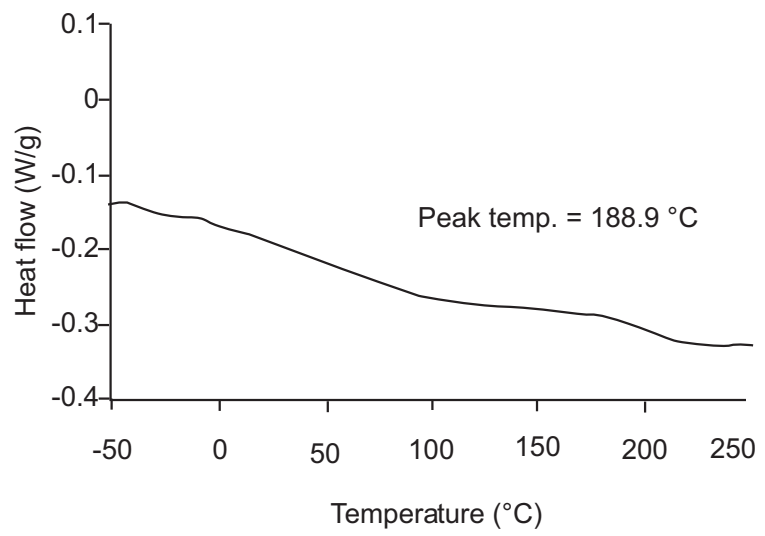

Fig. 3. Re-ramp of isothermal unsaturated polyester resin at temperature range -50 to $300{ }^{\circ} \mathrm{C}$.

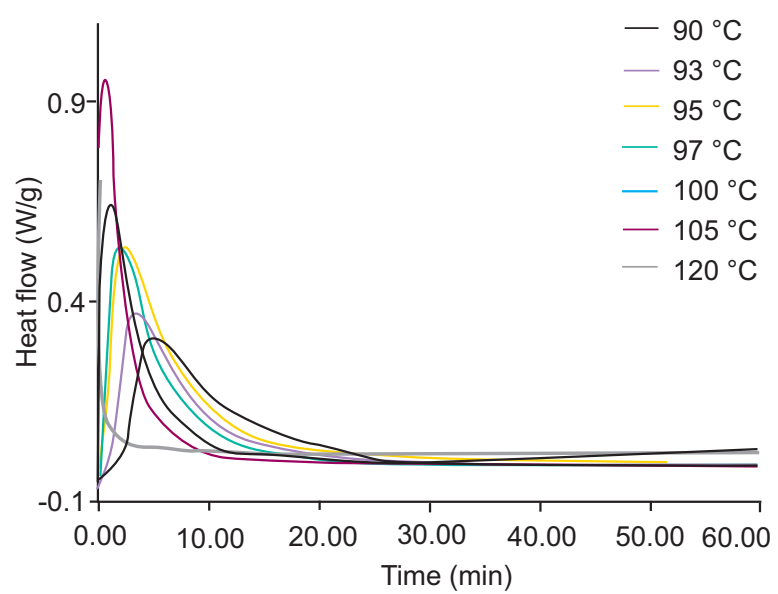

Fig. 4. Isothermal thermograms of unsaturated polyester resin at different temperatures. 


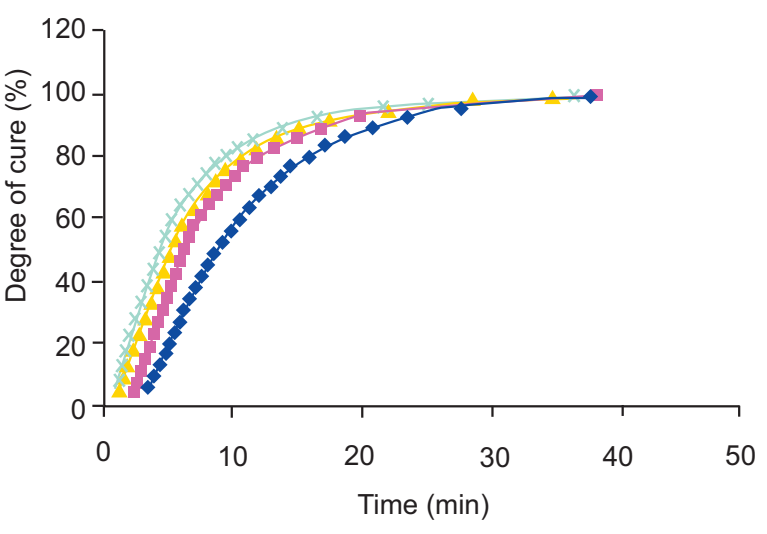

$\rightarrow 90^{\circ} \mathrm{C}-93^{\circ} \mathrm{C}-95^{\circ} \mathrm{C} * 97^{\circ} \mathrm{C}$

Fig. 5. Degree of conversion against curing time at temperatures $90,93,95$ and $97^{\circ} \mathrm{C}$.

for $90,93,95$ and $97^{\circ} \mathrm{C}$ as shown in Fig. 5 by using equation 2.

Salla and Ramix (1995) established that the isothermal kinetic analysis through isoconventional adjustment is the best method that offers the most accurate results for unsaturated polyester resin cure kinetics. Derivation of isoconventional adjustment $\operatorname{lnt}=\mathrm{A}+\mathrm{E} / \mathrm{RT}$ as established by Salla and Ramix (1994) is substituting the Arrhenius equation 3 into the rate equation 4 recording and integrating between curing time $\mathrm{t}=0$ where $\alpha=0$ and time $t$ with degree of conversion, and taking logarithms, the degree of conversion is $\ln \mathrm{t}=\mathrm{A}+\mathrm{E} / \mathrm{RT}$, where A takes the following value:

$\mathrm{A}=\ln [f \mathrm{~d} \alpha / f(\alpha)]-\ln \mathrm{k}_{0}$

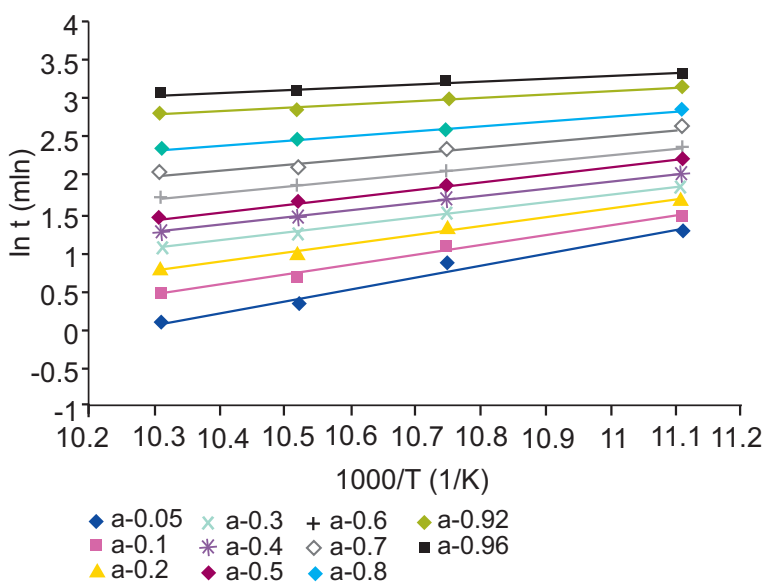

Fig. 6. . Correlation of logarithms of time against the inverse of temperature for different degree of conversion according to $\ln \mathrm{t}=$ $\mathrm{A}+\mathrm{E} / \mathrm{RT}$.
According to equation 8 the linear relationship $\ln \mathrm{t}$ against $\mathrm{T}$ at different temperatures is shown in Fig. 6. The activation energy $\mathrm{E}$ and constant $\mathrm{A}$ can be determined from the slope and intercept line least square fitted to data. Curing times at $120{ }^{\circ} \mathrm{C}$ was determined by extra plotting the straight line shown in Fig. 6. At $120{ }^{\circ} \mathrm{C}(1 / \mathrm{T}=8.3$ according to $\ln \mathrm{t}=\mathrm{A}+\mathrm{E} / \mathrm{RT})$ series of points along $\ln t$ at different degrees of conversions were noted, by taking anti-log of $\ln t$, time was also determined at different degrees of conversion which is plotted against the degree of conversion in Fig. 7. According to this prediction $95 \%$ of UP resin must take 33 min to fully cure, while according to isothermal DSC run UP resin will take $60 \mathrm{~min}$ at $120^{\circ} \mathrm{C}$ to be fully cured (see Fig. 2).

Degree of cure. $1 \mathrm{~mL}$ of UP resin samples were cured for different intervals of time with microwave radiation using a solid state amplifier having frequency range $2.3-2.7 \mathrm{GHz}$ and maximum power $30 \mathrm{~W}$. The network analyzer was used as microwave signal source. Figure 8 shows the

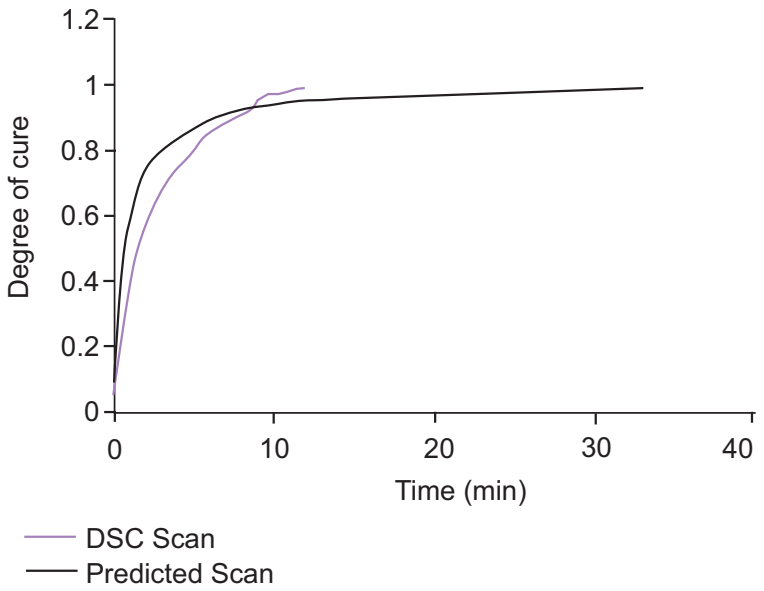

Fig. 7. Degree of conversion against time.

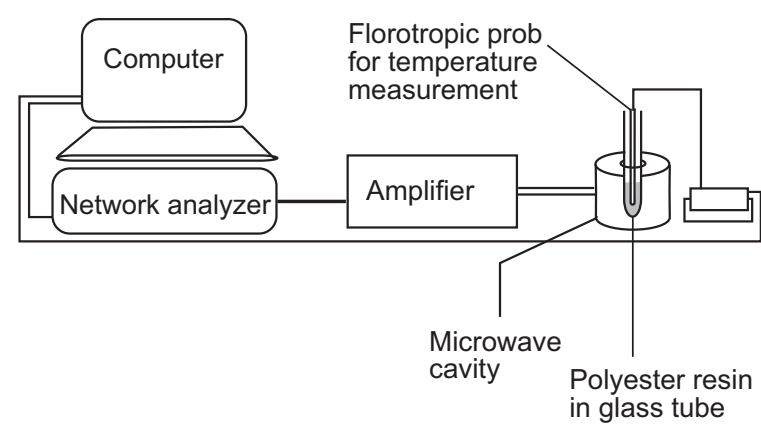

Fig. 8. Systematic diagram of microwave curing apparatus. 


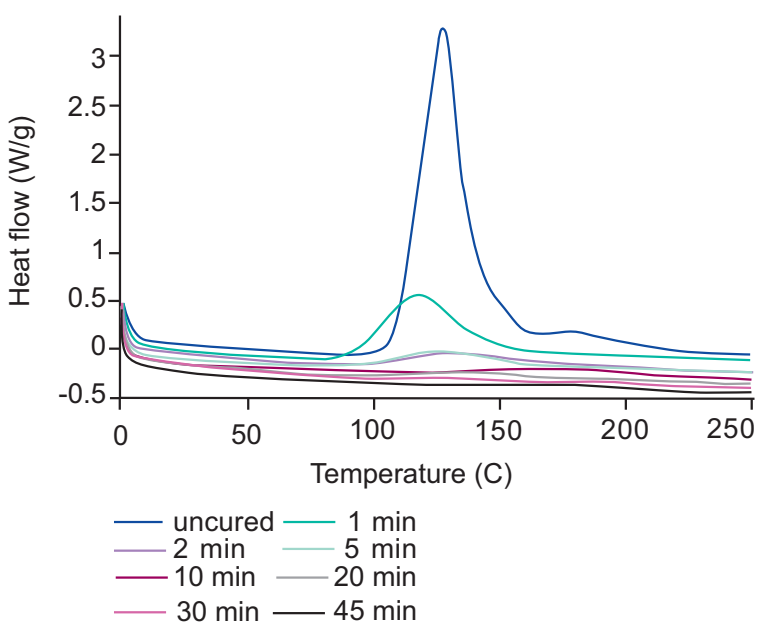

Fig. 9. DSC thermograms of UP resin cured at different time intervals in microwave at $120^{\circ} \mathrm{C}$.

systematic diagram of microwave processing. Figure 9 shows the DSC thermograms of microwaved samples cured for temperature range of $-50{ }^{\circ} \mathrm{C}$ to $300{ }^{\circ} \mathrm{C}$ at a heating rate of $20^{\circ} \mathrm{C} / \mathrm{min}$. The degree of conversion at each temperature was determined by using the following expression

$\alpha=1-\left(\Delta \mathrm{H}_{\mathrm{t}} / \Delta \mathrm{H}_{\mathrm{dyn}}\right)$

Where:

$\Delta \mathrm{H}_{\mathrm{t}}=$ the heat released during the time $\mathrm{t}$ and $\Delta \mathrm{H}_{\mathrm{dyn}}=$ total heat released i.e. the heat of reaction for uncured resin at the same rate of heating. Figure 10 shows the degree of conversion against time for microwave cured UP resin and it indicates that $67 \%$ resin is cured in $1 \mathrm{~min}$. In microwave heating polymer molecules are heated directly due to the relaxation of the polarisation of dipoles along

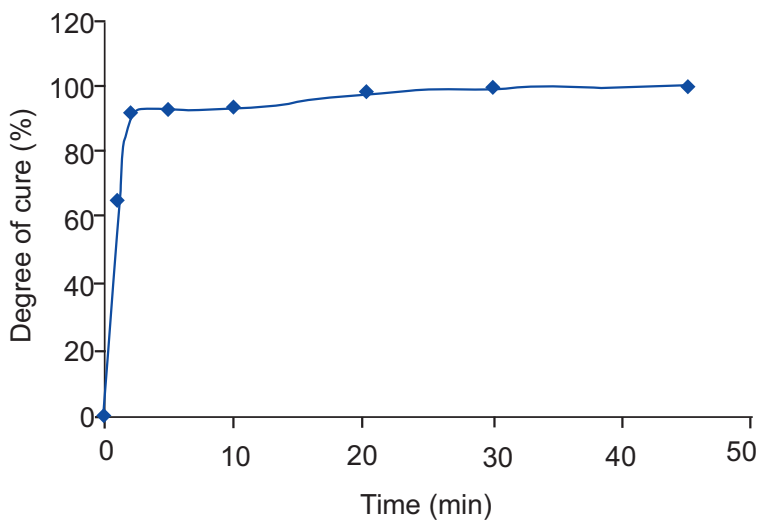

Fig. 10. Degree of conversion against time for microwave cured UP resin. the electric field. The carboxylic $\left(\mathrm{HO}_{2} \mathrm{C}-\right)$ segments of fumaric residues are the most dielectrically active polar groups. The induced polymer polarisation in the network structure will increase the molecular mobility which resulted in the acceleration of the curing reaction during early stages of the process. After 15 min the conversion occurred slowly because it might be possible that the remaining $\mathrm{C}=\mathrm{C}$ bonds are buried in the microgel structure. Thus the full conversion may not be achieved even at high temperature (Hanemann et al., 2010; Huang and Chen, 1993; 1992; Jacobs and Jones, 1992; Yang and Lee, 1988; Tinga and Nelson, 1973).

Rheological characterisation of UP resin. It is fundamental to determine the viscosity-temperature relationship of resins used for Resin Transfer Moulding processing. The rate of advance of flow front is coupled inversely to the resin viscosity. The parameter of interest is the time in which the viscosity of resin rises to a value where further impregnation and wetting of fibre reinforcement is impractical. Rheometers determine the change in viscosity by determining the torsional resistance of the resin at preset shearing rate. Test is terminated once the torque achieves a certain threshold in order to avoid damage. The Rheological characterization of UP resin was carried out with parallel plate rheometer; Rheometric Scientific RMS 800 , using $50 \mathrm{~mm}$ parallel plates and the gap between plates was set $0.5 \mathrm{~mm}$. The test was undertaken with a set frequency of $1 \mathrm{~Hz}$ and shear strain of $2.5 \%$.

Figure 11 indicates the rheological changes for a mixture of UP resin and 1\% Benzyl peroxide catalyst. But it does not show any changes in $\mathrm{G}^{\prime}, \mathrm{G}^{\prime \prime}$ and viscosity after 200 sec because the reaction at $120^{\circ} \mathrm{C}$ was so fast that the resin

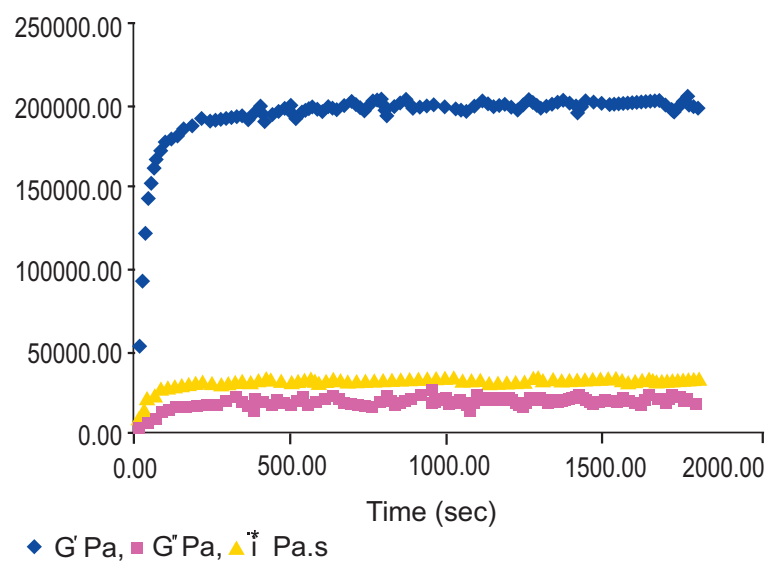

Fig. 11. Changes in steady viscosity (i), dynamic modulus $G^{\prime}$ and loss modulus $G^{\prime \prime}$ with time at temperature $120^{\circ} \mathrm{C}$. 
cured during the stabilisation of instrument. However, the maximum value of $\mathrm{G}^{\prime \prime}$ corresponding to the time can be seen, after which $\mathrm{G}^{\prime}$ remains constant. Gelation is defined as the point at which the curing system transforms suddenly from viscous liquid to an elastic gel (Yang and Lee, 1988). Tung and Dynes, suggested that, the time at which the crossover of $\mathrm{G}^{\prime}$ and $\mathrm{G}^{\prime \prime}$ occurs during isothermal curing can be taken as gel point (Tung and Dynes, 1982). Winter and Chambon also took this as gelation time, though indicating that for many systems the gel point may not be equal to the one calculated at $G^{\prime}=G^{\prime \prime}$ (Whiter and Chambon, 1987). A well-accepted indicator for occurrence of gelation is a rapid increase in viscosity. An accepted method to define gel point is when viscosity reaches a value of either $10^{4}$ or $10^{3} \mathrm{~Pa}$.s. In this study, the gel point appears to be somewhat earlier than those determined from $10^{4}$ or $10^{3}$ Pa.s. In case of UP resin, these major changes in rheological properties occur at the beginning of the curing reaction i.e. for conversions lower than 5\% in different manner to epoxy resin. The change in viscosity with time is shown in Fig. 12, which was recorded by raising the temperature

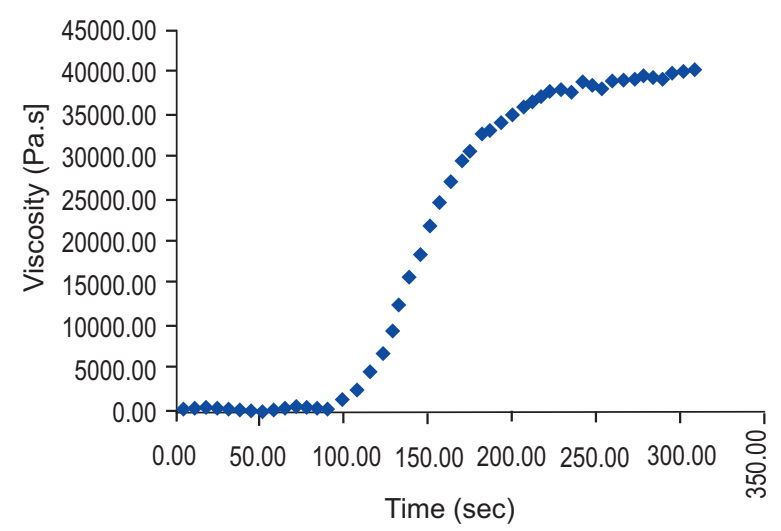

Fig. 12. Change in viscosity with time at $120{ }^{\circ} \mathrm{C}$.

of hot plates from $90^{\circ} \mathrm{C}$ to $120^{\circ} \mathrm{C}$. It can be seen that in case of unsaturated polyester resin the gel point reached before $10^{4} \mathrm{~Pa}$.s and crosslinking took place in approximately $100 \mathrm{sec}$.

\section{Conclusion}

The curing process of unsaturated polyester resin initiated with benzoyl peroxide was studied by differential scanning calorimetry (DSC). The kinetic analysis was performed by mean of an empirical model. The isothermal and non-isothermal DSC runs were performed to determine the time and temperature required to cure the UP resin. The isothermal test predicted that UP resin cured at temperature range of $90{ }^{\circ} \mathrm{C}-120{ }^{\circ} \mathrm{C}$. However, the time predicted by non-isothermal test seemed to be incorrect since the sum of residual heat and isothermal heat was not equal to the dynamic heat which indicated that the heat was lost during the stabilisation of calorimeter. The time require to cure the UP resin was then predicted using the isothermal kinetic analysis through isoconversional adjustment which indicated that $95 \%$ of UP resin will cure in $33 \mathrm{~min}$ at $120{ }^{\circ} \mathrm{C}$. The curing of UP resin using microwaves at different interval of time however, indicated that $67 \%$ of UP resin cures in $1 \mathrm{~min}$. The crosslinking reaction of UP resin at $120{ }^{\circ} \mathrm{C}$ using microwaves was so fast that it was impossible to fully cure the resin due to burial of $\mathrm{C}=\mathrm{C}$ bonds in the microgel structure. In rheological study of UP resin; curing also took place during the stabilisation of equipment at $120{ }^{\circ} \mathrm{C}$ which further confirmed that UP resin crosslink in $100 \mathrm{sec}$ at $120^{\circ} \mathrm{C}$.

\section{Acknowledgements}

The Material Science Center, UMIST, Manchester is gratefully acknowledged for technical support.

\section{References}

Avella, M., Martuscelli, E., Mazzola, M. 1985. Kinetic study of the cure reaction of unsaturated polyester resins. Journal of Thermal Analysis and Calorimetry, 30: 1359-1366.

Bu, Z., Hu, J., Li, B. 2014. Novel silicon-modified phenolic novolac resins: Non-isothermal curing kinetics, and mechanical and thermal properties of their biofiber-reinforced composites. Thermochimica Acta, 575: 244-253.

Fink, J.K. 2013. Unsaturated polyester resins. In: Reactive Polymers Fundamentals and Applications, pp. $1-48,2^{\text {nd }}$ edition, William Andrew Publishing, New York, USA.

Hanemann, T., Schumacher, B., Haußelt, J. 2010. Polymerization conditions influence on the thermomechanical and dielectric properties of unsaturated polyester-styrene-copolymers. Microelectronic Engineering, 87: 15-19.

Horic, K., Mita, I., Kambe, H. 1969. Calorimetric investigation of polymerization reactions. II. Copolymerization of diethyl fumarate with styrene. Journal of Polymer Science: Part-A Polymer Chemistry, 7: 2561- 2567.

Huang, Y.J., Chen, C.J. 1993. Curing of unsaturated polyester resin: Effect of co-monomer Composition. 
III-Medium Temperature Reaction. Journal of Applied Polymer Science, 48: 151- 165.

Huang, Y.J., Chen, C.J. 1992. Curing of unsaturated polyester resin: Effect of co-monomer composition, II-High Temperature Reaction. Journal of Applied Polymer Science, 47: 1533-1549.

Jacobs, P.M., Jones, F.R. 1992. The influence of heterogeneous crosslink density on the thermo-mechanism and hydrothermal properties of unsaturated polyester resin: I-Thermo-mechanical Response. Polymer, 33: 1418- 1422.

Jankoviæ, B. 2010. The Kinetic analysis of isothermal curing reaction of an unsaturated polyester resin: Estimation of the density distribution function of the apparent activation energy. Chemical Engineering Journal, 162: 331-340.

Lewis, F.M., Walling, C., Cummings, W., Briggs, E.R., Mayo, F.R. 1948. Copolymerization. IV. Effects of temperature and solvents on monomer reactivity ratios. Journal of American Chemical Society, 70: 1519-1523.

Martin, J.L., Cadenato, A., Salla, J.M. 1997. Comparative Studies on the non-isothermal DSC curing kinetics of an unsaturated polyester resin using free radicals and empirical models. Thermochimica Acta, 306: 115-126.

Salla, J.M., Ramix, X. 1995. Effect of the inhibitor on the curing of an unsaturated polyester resin. Polymer, 36: $3511-3521$.
Salla, J.M., Ramix, X. 1994. A kinetic study of the effect of three catalytic systems on the curing of an unsaturated polyester resin. Journal of Applied Polymer Sciences, 51: 453-462.

Severini, F., Gallo, R.J. 1985. Differential scanning calorimetry study of the thermal decomposition of peroxides in the absence of a solvent. Journal of Thermal Analysis and Calorimetry, 30: 841-847.

Tinga, W. R., Nelson, S.O. 1973. Measurement of microwave dielectric properties materials. Journal of Microwave Power, 8: 23-65.

Tung, C.Y.M., Dynes, P.J. 1982. Relationship between viscoelastic properties and gelation in thermosetting systems. Journal of Applied Polymer Science, 27: 569-574.

Vargas, M.A., Sachsenheimer, K., Guthausen, G. 2012. In-situ investigation of the curing of polyester resin. Polymer Testing, 31: 127-135.

Whiter, H.H., Chambon, F. 1987. Analysis of linear viscoelasticity of a crosslinking polymer at the gel point. Journal of Rheology, 30: 367-383.

Wuzella, G., Kandelbauer,A., Mahendran, A.R., Teischinger, A. 2011. Thermochemical and isoconversional kinetic analysis of a polyester-epoxy hybrid powder coating resin for wood based panel finishing. Progress in Organic Coating, 70: 186-191.

Yang, Y.S., Lee, L. 1988. Microstructure formation in the cure of unsaturated polyester resin. Polymer, 29: 1793-1800. 